\title{
Stroke Volume and Left Ventricular Output in Preterm Infants with Patent Ductus Arteriosus ${ }^{1}$
}

\author{
WOLFGANG LINDNER, MONIKA SEIDEL, HANS T. VERSMOLD, CHRISTOPH DÖHLEMANN, \\ AND KLAUS P. RIEGEL \\ Department of Pediatrics [W.L., M.S., C.D., K.P.R.] and Division of Neonatology [H.T.V.], Department of \\ Gynecology and Obstetrics Klinikum GroBhadern, University of Munich, F.R.G.
}

\begin{abstract}
To assess the effect of patent ductus arteriosus (PDA) on left ventricular output (LVO) we studied stroke volume (SV), LVO, and heart rate (HR) in 21 very low birth wt preterm neonates with clinically symptomatic PDA before and after surgical ligation. Six additional infants were also studied before PDA with left-to-right shunt was detectable by the pulsed Doppler technique. Gestational age (median and range) was 28 (24-32) wk. SV was measured by duplex Doppler and M-mode echocardiography, and LVO was calculated as product of SV and HR. LVO was $419(305-562) \mathrm{mL} / \mathrm{min} / \mathrm{kg}$ during symptomatic PDA. It decreased to 246 (191-292) $\mathrm{mL} / \mathrm{min} /$ $\mathrm{kg}$ after ligation $(n=21, p<0.001)$. SV was $2.69(1.98$ 4.10) $\mathrm{mL} / \mathrm{kg}$ during symptomatic PDA decreasing to 1.63 $(1.22-1.98) \mathrm{mL} / \mathrm{kg}$ after ductal closure $(n=21, p<0.001)$. HR did not change after ductal closure. In the six infants with three examinations, LVO and SV were normal before detectable ductal left-to-right shunt and after ligation, but LVO was increased by $59.5 \pm 23 \%$ (mean \pm SD) $(p<$ $0.05)$, and $S V$ by $60 \pm 32 \%(p<0.05)$ during symptomatic PDA. In conclusion, preterm neonates with RDS, requiring mechanical ventilation, increased LVO during symptomatic PDA by increasing their SV, and not by changing their HR. (Pediatr Res 27: 278-281, 1990)
\end{abstract}

\section{Abbreviations}

AoBFV, aortic blood flow velocity $(\mathrm{cm} / \mathrm{s})$

HR, heart rate (bpm)

$\mathrm{LVO}$, left ventricular output $(\mathrm{mL} / \mathrm{min} \cdot \mathrm{kg})$

L-R, left-to-right

mBP, mean systemic blood pressure

PDA, patent ductus arteriosus

RDS, respiratory distress syndrome

$\mathrm{GA}$, gestational age

$\mathrm{SV}$, stroke vol $(\mathrm{mL} / \mathrm{kg})$

LVO is determined by SV and HR. It is well known that neonates can regulate LVO by changing their HR. It has also been stated that newborn infants, because of their low contractile reserve, can increase LVO only by increasing their $\operatorname{HR}(1,2)$. Inasmuch as noninvasive assessment of LVO in neonates by Doppler echocardiography became an established method (3), several reports on LVO in neonates have been published (4-6), but only little information is available on intraindividual changes of SV in preterm neonates (7). PDA, a common problem in

Received February 10, 1989; accepted October 19, 1989.

Correspondence W. Lindner, M.D., Department of Pediatrics, University of Munich, Lindwurmstr. 4, D-8000 München 2, F.R.G

1 Presented in part at the ESPR meeting, Oslo, June 1988 (Pediatr Res 1988;24:281A. preterm neonates with RDS, should be associated with an increased LVO, if PDA is hemodynamically significant. We therefore studied the intraindividual changes of SV, HR, LVO, and $\mathrm{mBP}$ in preterm infants with RDS and symptomatic PDA.

\section{MATERIALS AND METHODS}

We studied 21 preterm neonates with a symptomatic PDA before and after surgical ligation. Four of these infants were transferred to our unit from other hospitals for ductal ligation at the age of $21(15-22) \mathrm{d}$. Six additional patients were studied before a ductal L-R shunt was detectable, during symptomatic PDA, and after ligation. The time between ductal closure and LVO measurement (mean \pm SD) was $2 \pm 1.9 \mathrm{~d}$. In infants with clinical signs such as systolic murmur, precordial pulsations, and bounding pulses, the PDA was verified by pulsed Doppler examination of the blood flow in the main pulmonary artery. The PDA was considered significant, if respiratory deterioration, a decrease of urinary output, or gastrointestinal problems were present and could not be related to other conditions than PDA. Exclusion criteria were cardiac malformations or heart failure (verified by echocardiography), anemia, hypoxemia, and therapy with indomethacin. The study infants did not receive indomethacin because contraindications (renal failure, intracranial hemorrhage, signs of beginning necrotizing enterocolitis) were present or the immediate closure of the PDA was required due to the clinical state of the infant.

The GA (median and range) of the study infants was 28 (2432) wk. All infants required intermittent positive pressure ventilation due to RDS (Sechrist Infant Ventilator, model IV 100B, Sechrist Industries Inc., Anaheim, CA). Ventilator settings were adjusted to keep arterial or transcutaneous blood gases within the range of 35-45 torr $\left(\mathrm{PCO}_{2}\right)$ and $50-70$ torr $\left(\mathrm{PO}_{2}\right)$. Data on ventilator settings, blood gases, hematocrit, fluid intake, age, and wt are given in Table 1. Seven infants with a GA of 27 (24-32) wk received dopamine and dobutamine during all examinations (before and after ligation). These infants had clinical signs of a large L-R shunting PDA at the age of $4(2-21) \mathrm{d}$ and urinary output was decreased. Dopamine $(2-4 \mu \mathrm{g} / \mathrm{kg} / \mathrm{min})$ was given to improve renal function and dobutamine $(5-10 \mu \mathrm{g} / \mathrm{kg} / \mathrm{min})$ for inotropic support. HR of these infants was $152(143-154) \mathrm{bpm}$ and did not differ from the whole group, mBP was $30(22-37)$ torr and was slightly higher compared to the infants without inotropic drugs. All 27 infants were sedated with phenobarbital.

The Doppler echocardiographic examinations were performed with a duplex Doppler device (Ultramark 8, Squibb Medical Systems, Bellevue, NY). An angled $7.5 \mathrm{MHz}$ transducer was used. The wall filter was set at $200 \mathrm{~Hz}$. Intensity at the transducer surface was $15.5 \mathrm{~mW} / \mathrm{cm}^{2}$. The Doppler spectral data were analyzed using the fast Fourier transformation and displayed as flow velocities $(\mathrm{cm} / \mathrm{s})$.

Doppler examinations were done in the common pulmonary artery and in the ascending aorta. The pulmonary artery was 
Table 1. Clinical data (median and range) of study infants*

\begin{tabular}{lccc}
\hline & $\begin{array}{c}\text { Before PDA L-R } \\
\text { shunt } \\
(n=6)\end{array}$ & $\begin{array}{c}\text { With symptomatic } \\
\text { PDA }(n=27)\end{array}$ & $\begin{array}{c}\text { After ligation } \\
(n=27)\end{array}$ \\
\hline Gestational age $(\mathrm{wk})$ & $27(26-30)$ & $28(24-32)$ & $14(5-24)$ \\
Age $(\mathrm{d})$ & $3(1-7)$ & $8(2-22)$ & $1000(630-2180)$ \\
$\mathrm{Wt}(\mathrm{g})$ & $810(700-1150)$ & $870(590-2150)$ & $0.44(0.32-0.51)$ \\
$\mathrm{Hematocrit}(\mathrm{L} / \mathrm{L})$ & $0.47(0.42-0.52)$ & $0.42(0.33-0.52)$ & $150(90-200)$ \\
Fluid intake $(\mathrm{mL} / \mathrm{kg} \cdot \mathrm{d})$ & $95(76-170)$ & $100(80-150)$ & $12(8-19)$ \\
PIP $\left(\mathrm{cm} \mathrm{H} \mathrm{H}_{2} \mathrm{O}\right)$ & $11(9-13)$ & $14(8-33)$ & $3(2.0-4.0)$ \\
$\mathrm{PEEP}\left(\mathrm{cm} \mathrm{H} \mathrm{H}_{2} \mathrm{O}\right)$ & $3(2.0-3.0)$ & $3(1.5-4.0)$ & $0.32(0.21-0.80)$ \\
$\mathrm{FiO}_{2}$ & $0.25(0.21-0.30)$ & $0.30(0.21-0.80)$ & $37(32-47)$ \\
$\mathrm{PCO}_{2}$ (torr) & $33(30-40)$ & $60(50-83)$ & $59(48-83)$ \\
$\mathrm{PO}_{2}$ (torr) & $58(54-67)$ &
\end{tabular}

* PIP, peak inspiratory pressure; PEEP, positive endexpiratory pressure; $\mathrm{FiO}_{2}$, fractional inspiratory $\mathrm{O}_{2}$ concentration.
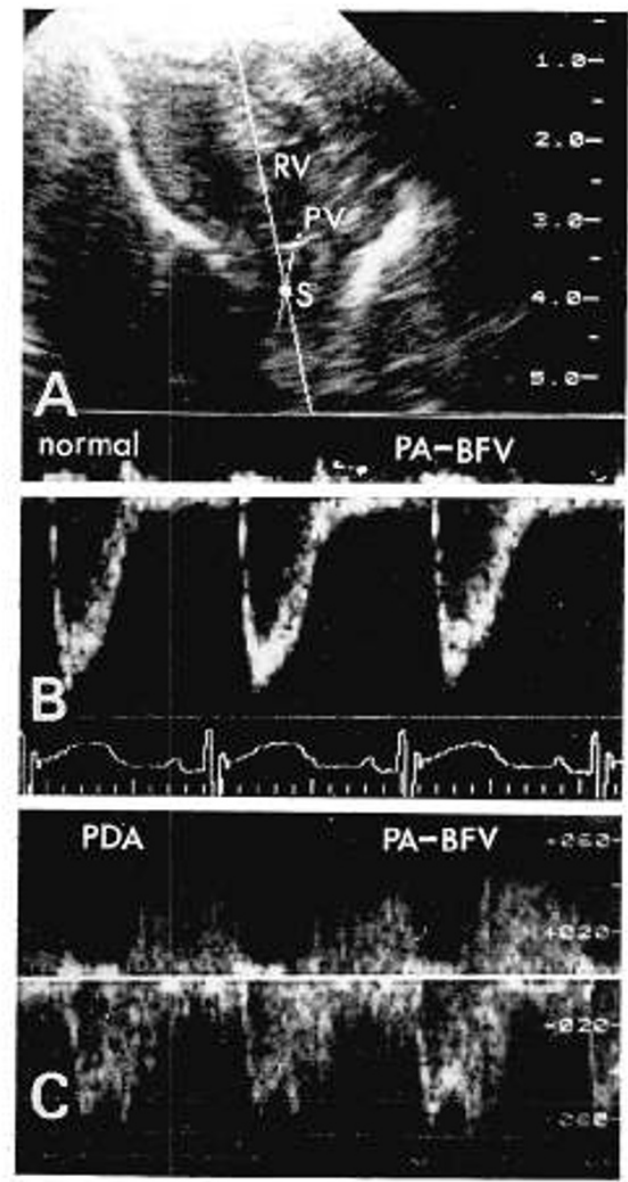

Fig. 1. $A$, right ventricular outflow tract $(R V)$ and main pulmonary artery from the subcostal view. $P V$, pulmonic valve; $S$, sample volume. $B$, normal Doppler pattern of pulmonary artery blood flow velocity $(P A$ $B F V)$. $C$, Doppler pattern of pulmonary artery blood flow velocity during PDA.

imaged from the subcostal view (Fig. 1), the ascending aorta either from the suprasternal notch or from the subcostal view (Fig. 2). The individual transducer position was constant for all examinations. To validate the comparability of these two measuring sites, AoBFV was measured in 10 infants from both transducer positions. The difference of AoBFV was $2.4 \pm 2.0 \%$ and was not significant. The sample volume was positioned just distal to the aortic valve. The angle between the Doppler beam and the ascending aorta was measured and corrected, if it was larger than $15^{\circ}$. Minimal transducer movements were made to detect the maximum flow velocity.

The Doppler tracings were displayed at $100 \mathrm{~mm} / \mathrm{s}$ and recorded on video tape. Measurements were made off line when
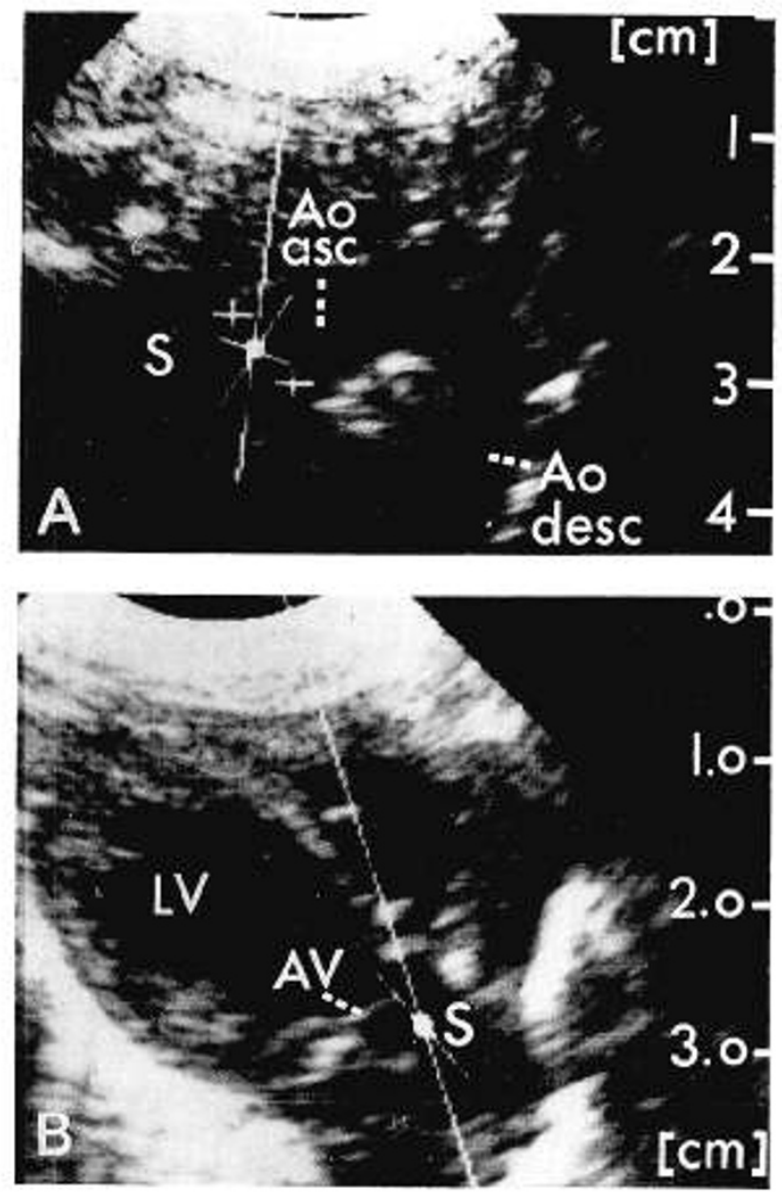

Fig. 2. Two-dimensional image of the ascending aorta. Transducer position: $A$, suprasternal; $B$, subcostal. $S$, sample volume; $L V$, left ventricle.

Table 2. Doppler-echocardiographic data (median and range)

\begin{tabular}{|c|c|c|}
\hline & $\begin{array}{l}\text { With symptomatic } \\
\operatorname{PDA}(n=21)\end{array}$ & $\begin{array}{l}\text { After ligation } \\
\quad(n=21)\end{array}$ \\
\hline Stroke volume $(\mathrm{mL} / \mathrm{kg})$ & $2.69(1.98-4.10)^{*}$ & $1.63(1.22-1.98)$ \\
\hline $\begin{array}{l}\text { Left ventricular output } \\
\qquad(\mathrm{mL} / \mathrm{min} / \mathrm{kg})\end{array}$ & $419(305-562)^{*}$ & $246(191-292)$ \\
\hline $\mathrm{HR}(\mathrm{bpm})$ & $150(124-182)$ & $150(120-171)$ \\
\hline $\begin{array}{l}\text { Mean blood pressure } \\
\text { (torr) }\end{array}$ & $21(15-37) \dagger$ & $30(21-55)$ \\
\hline
\end{tabular}

$* p<0.001$

$\dagger p<0.01$. 


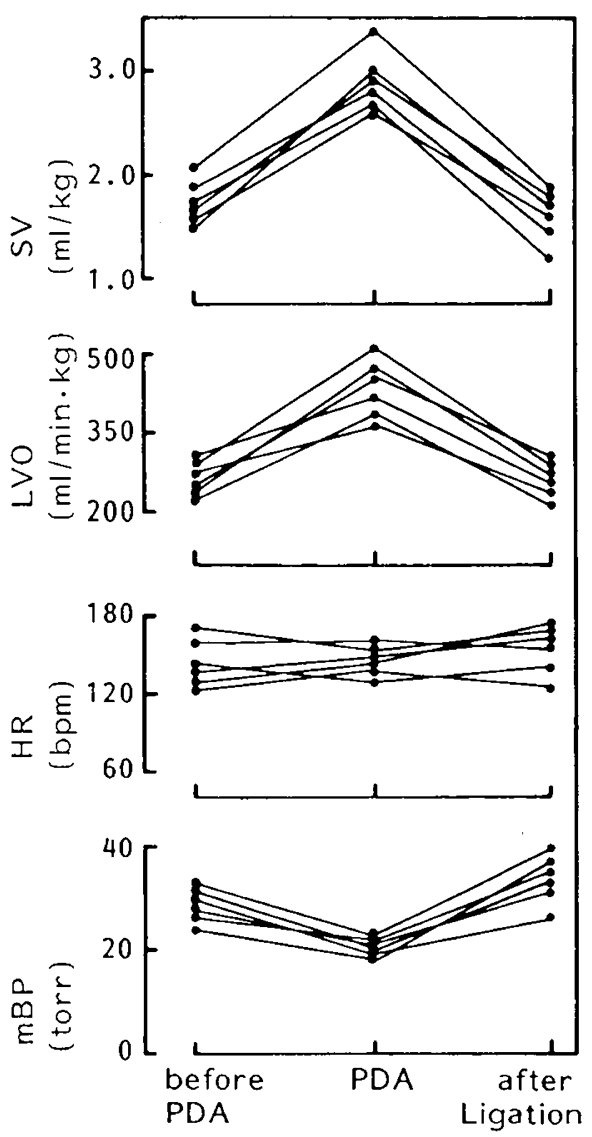

Fig. 3. Sequential changes in SV, left ventricular output (LVO) HR, and $\mathrm{mBP}$ in six preterm infants with RDS before a detectable ductal L$\mathrm{R}$ shunt $(I)$, at symptomatic PDA $(I I)$, and after ligation of the PDA (III). SV, LVO, and $\mathrm{mBP}$ (I versus II and II versus III): $p<0.05$; HR no significant differences.

the blood flow velocity was stable over 10 cardiac cycles. Mean AoBFV was determined for each cardiac cycle as area under the aortic systolic flow curve using the electronical calipers of the instrument. This area was calculated for each single stroke according to the method of Main et al. (8) as product of maximum systolic flow velocity and left ventricular ejection time divided by two. HR was derived from a simultaneously recorded ECG lead. The inner aortic diameter was measured by M-mode with two-dimensional control to assure that the M-mode beam was positioned perpendicular to the aorta at the level of the aortic valve annulus (parasternal long axis) (9). The aortic diameter was measured at the time of aortic valve closure. A clear signal from the aortic endothelium and a complete midstanding aortic valve echo were obtained in all studies. Aortic area was calculated using the equation of a circle. SV was calculated as the product of mean AoBFV and aortic area, and LVO as the product of SV and HR. SV and LVO were related to body wt $(\mathrm{kg})$.

All measurements were made by the same examiner (W.L.). To validate the method, coefficients of variation were established for the different measurements. It was $2 \%$ for the mean AoBFV, $6 \%$ for the aortic diameter, $10 \%$ for SV, and $13 \%$ for LVO (10 examinations repeated within $1 \mathrm{~h}$ ).

Blood gases were monitored transcutaneously with combined $\mathrm{PO}_{2}$ and $\mathrm{PCO}_{2}$ electrodes (Kontron, Roche, Basel, Switzerland, or Sensormedics, Anaheim, CA), validated by arterial blood gases (AVL 945, AVL, Graz, Austria). Systemic blood pressure was measured by the Doppler method (Arteriosonde, Roche, Basel, Switzerland) and $\mathrm{mBP}$ calculated as diastolic $\mathrm{BP}+0.33 \times \mathrm{BP}$ amplitude.

Statistical evaluation included calculation of coefficients of variation, linear regression analysis, and group comparisons by the Wilcoxon and the Student's $t$ test for dependent variables. Standard distribution of the differences of SV and LVO were tested by the chi square test. The level of significance was set at $p<0.05$. The study was approved by the university's ethical committee and informed consent of parents was obtained.

\section{RESULTS}

$H R$. HR was not different at the time of symptomatic PDA and after ductal ligation in the whole group (Table 2). In the group of six infants studied also before PDA with L-R shunt, HR before and during ductal L-R shunt, and after ductal L-R shunt was similar (Fig. 3).

$S V$. In the group of six infants SV was similar before PDA with L-R shunt and after ductal closure, but increased by $60 \pm$ $32 \%$ (mean $\pm \mathrm{SD}$ ) during symptomatic PDA $(p<0.05)$ (Fig. 3 ). In the group of 21 infants SV decreased by $43 \pm 13 \%$ from an elevated to a normal level after ligation $(p<0.001)$ (Table 2$)$. Mean AoBFV was high during symptomatic PDA due to the high SV. Aortic root area did not change significantly during the study period.

$L V O$. Inasmuch as $\mathrm{HR}$ was not significantly different at the times of measurement, changes of LVO were proportional to the changes of SV. In the group of six infants, LVO was normal before ductal L-R shunt and after ligation, and elevated by 59.5 $\pm 23 \%$ during symptomatic PDA $(p<0.05)$ (Fig. 3 ). The mean decrease $(p<0.001)$ from LVO during symptomatic PDA to LVO after ductal closure in the group of 21 infants was $185 \pm$ $65 \mathrm{~mL} / \mathrm{kg} / \mathrm{min}(-41 \pm 11 \%$ ) (Table 2). LVO during symptomatic PDA and after ligation was not significantly related to gestational age. The magnitude of the change of LVO after ductal closure was not related to postnatal age and was not different in neonates with inotropic drugs $(-40 \pm 12 \%)(n=7)$ and in infants without inotropic drugs $(-41 \pm 10 \%)(n=20)$.

$m B P$. In the group of six infants $\mathrm{mBP}$ decreased during symptomatic PDA $(p<0.05)$ and increased by $67 \pm 24 \%$ after ductal closure $(p<0.05)$ (Fig. 3). In the group of 21 infants $\mathrm{mBP}$ increased by $62 \pm 48 \%(p<0.01)$ after ductal closure (Table 2$)$.

Pulmonary blood flow velocity. A normal laminar systolic blood flow with absent diastolic blood flow was found in all six infants studied before PDA with L-R shunt, and in all 27 infants after ductal closure. During symptomatic PDA the typical blood flow with holodiastolic reverse flow was present in all infants (Fig. 1).

\section{DISCUSSION}

Our study shows that under the hemodynamic conditions associated with symptomatic PDA, sick ventilated preterm neonates increased LVO by increasing SV and not HR.

The diagnosis of symptomatic PDA and its hemodynamic significance in this study was based on Doppler-echocardiographic and clinical criteria. Doppler assessment of a diastolic reverse flow in the main pulmonary artery is the most sensitive noninvasive method to detect L-R ductal shunt (10). Using this method we differentiated between infants with and without ductal L-R shunt. However, the hemodynamic relevance of a PDA with L-R shunt cannot be determined by this technique. Also the Doppler method is not suitable for direct quantification of ductal flow, the indirect estimation of ductal flow from preand postductal aortic flows (11) has not yet been validated, and M-mode data are not sensitive in the individual patient to assess the hemodynamic relevance of a PDA $(12,13)$. We therefore used common clinical criteria to decide if a PDA was symptomatic.

The increase of SV and LVO during symptomatic PDA in the study infants remain significant, if methodologic problems of Doppler determination of LVO are considered. The coefficients of variation for aortic diameter $(6 \%)$ and LVO $(13 \%)$ in this study agreed with data from other authors $(14,15)$. 
A recent cross-sectional study of LVO in preterm neonates with PDA (14) did not show an increased LVO. However, as stated by the authors, only two of the 12 infants fulfilled the criteria of a clinically significant PDA.

Animal studies suggest that the normal neonatal heart is already working at the upper limit of the Frank Starling curve $(1,2)$ and is not able to increase left ventricular SV if preload is raised. In contrast, we found a 2 -fold increase in SV above normal levels (16) in sick preterm neonates with increased preload due to ductal L-R shunt, whereas heart rate remained unchanged. This finding is similar to animal data of Clyman et al. (17). They also found an increase in left ventricular SV and a constant HR in fetal lambs with PDA and RDS. The authors hypothesized that the associated reduced left ventricular afterload during PDA is important for the increase of SV in lambs (18). The lower mean arterial blood pressure in our infants during PDA may also indicate a decreased left ventricular afterload, which could contribute to the ability of the preterm neonate to increase left ventricular SV.

Seven of our infants received inotropic drugs throughout the study. These drugs increase left ventricular contractility and can increase SV and LVO (7). However, the changes in SV and LVO during symptomatic PDA in these infants did not differ from that of neonates without these drugs.

Why did HR remain constant despite the demand for an increased LVO during ductal L-R shunt? We cannot explain this phenomenon, which has also been observed by Clyman et al. (18) in lambs under similar conditions. We can only speculate that, as in adults with cardiac failure (19), the sympathetic control of HR may be impaired in the neonatal heart, when the additional workload of a significant PDA is present.

In conclusion, human preterm neonates with symptomatic PDA and RDS, requiring mechanical ventilation, adapted their LVO by increasing SV and not HR. At least for the condition of a L-R shunting PDA our results favor the concept that SV is the major determinant for neonatal LVO.

\section{REFERENCES}

1. Teitel DF, Sidi D, Chin T, Brett C, Heyman MA, Rudolph AM 1985 Developmental changes in myocardial contractile reserve in the lamb. Pediatr Res 19:948-955
2. Romero TE, Friedman WF 1979 Limited left ventricular response to volume overload in the neonatal period: a comparative study with the adult animal. Pediatr Res 13:910-915

3. Alverson DC, Eldridge M, Dillon T, Yabek SM, Berman W 1982 Noninvasive pulsed Doppler determination of cardiac output in neonates and children. $J$ Pediatr 101:46-50

4. Walther FJ, Siassi B, Ramadan NA, Wu PYK 1984 Cardiac output in newborn infants with transient myocardial dysfunction. J Pediatr 107:781-785

5. Walther FJ, Siassi B, King J, Wu PYK 1985 Cardiac output in infants of insulin-dependent diabetic mothers. J Pediatr 107:109-114

6. Alverson DC, Eldridge MW, Johnson JD, Burstein R, Papile L, Dillon T, Yabek S, Berman W 1983 Effect of patent ductus arteriosus on left ventricular output in preterm infants. J Pediatr 102:754-757

7. Padbury JF, Agata Y, Baylen BG, Ludlow JK, Polk DH, Goldblatt E, Pescetti J 1987 Dopamine pharmacokinetics in critically ill newborn infants. J Pediatr 1 10:293-298

8. Main J, Nanda NC, Saini VD 1985 Clinical useful Doppler calculations and illustrative case examples. In: Nanda NC (ed) Doppler Echocardiography, 1st ed. Igaku-Shoin, New York, pp 496-499

9. Morrow WR, Murphy Jr DJ, Fisher DJ, Hutha JC, Jefferson LS, Smith EO 1988 Continuous wave Doppler cardiac output: use in pediatric patients receiving inotropic support. Pediatr Cardiol 9:131-136

10. Stevenson JG, Kawalori I, Guntheroth WG 1980 Pulsed Doppler echocardiographic diagnosis of patent ductus arteriosus: sensitivity, specificity, limitations and technical features. Cathet Cardiovasc Diagn 6:255-260

11. Drayton MR, Skidmore R 1987 Ductus arteriosus blood flow during first 48 hours of life. Arch Dis Child 62:1030

12. Kupferschmid CH, Lang D, Pohlandt F 1988 Sensitivity, specificity and predictive value of clinical findings, $M$-mode echocardiography and continuous-wave Doppler sonography in the diagnosis of symptomatic patent ductus arteriosus in preterm infants. Eur J Pediatr 147:279-282

13. Valdez-Cruz LM, Dudell GG 1981 Specifity and accuracy of echocardiographic and clinical criteria for diagnosis of patent ductus arteriosus in fluid restricted infants. J Pediatr 98:298-305

14. Mellander M, Larsson LE 1988 Effects of left-to-right ductus shunting on left ventricular output and cerebral blood flow velocity in 3-day-old preterm infants with and without severe lung disease. J Pediatr 113:101-109

15. Claflin KS, Alverson DC, Pathek D, Angelus P, Backstrom C, Werner C 1988 Cardiac output in the newborn. Reproducibility of the pulsed Doppler velocity method. J Ultrasound Med 7:311-315

16. Walther FJ, Siassi B, Ramadan N, Ananda AK, Wu PYK 1985 Pulsed Doppler determination of cardiac output in neonates: normal standards for clinical use. Pediatrics 76:829-833

17. Clyman RI, Mauray F, Heyman MA, Roman C 1987 Cardiovascular effects of a patent ductus arteriosus in preterm lambs with respiratory distress. $\mathrm{J}$ Pediatr 111:579-587

18. Clyman RI, Roman C, Heyman MA, Mauray F 1987 How a patent ductus arteriosus effects the premature lamb's ability to handle additional volume loads. Pediatr Res 22:531-535

19. Goldstein RE, Beiser GD, Stampfer M, Epstein SE 1975 Impairment of autonomically mediated heart rate control in patients with cardiac dysfunction. Circ Res 36:571-578 